\title{
Circulating concentrations of bovine pregnancy-associated glycoproteins and late embryonic mortality in lactating dairy herds
}

\author{
K. G. Pohler, ${ }^{* 1,2}$ M. H. C. Pereira, $\dagger^{2}$ F. R. Lopes, $\dagger$ J. C. Lawrence, $\ddagger$ D. H. Keisler, ${ }^{*} M$. F. Smith, ${ }^{*}$ \\ J. L. M. Vasconcelos, $†$ and J. A. Green*3 \\ *Division of Animal Sciences, University of Missouri, Columbia 65211 \\ †Departamento de Produção Animal, Faculdade de Medicina Veterinária e Zootecnia, São Paulo State University, Botucatu, São Paulo, \\ Brazil 18168-000 \\ †ldexx Laboratories Inc., Westbrook, ME 04092
}

\section{ABSTRACT}

The objectives of these experiments were as follows: (1) to determine the association between circulating concentrations of pregnancy-associated glycoproteins (PAG) and late embryonic mortality (EM) in lactating dairy cattle following fixed-time artificial insemination (TAI) on d 0 or timed embryo transfer (TET) on d 7 , (2) to identify a circulating concentration of PAG on d 31 below which late EM would be likely to occur, and (3) to identify when during gestation (d 31-59) late EM is occurring. Cows were diagnosed pregnant on $\mathrm{d}$ 31 of gestation based on presence of a fetal heartbeat and reconfirmed to be pregnant on d 59 of gestation. Late EM occurred when a cow had a viable embryo on d 31 of gestation but not on d 59 following TAI or TET. Only pregnant cows on $\mathrm{d} 31$ were included in the analysis (TAI-maintained, $\mathrm{n}=413$; TAI-EM, $\mathrm{n}=77$; TET-maintained, $\mathrm{n}=238$; TET-EM, $\mathrm{n}=47$ ). Cows that were pregnant at d 31 of gestation and maintained the pregnancy until d 59 had significantly higher circulating concentrations of PAG at d 31 of gestation compared with cows that experienced late EM between d 31 and 59 of gestation in both TAI and TET. To conduct a more stringent test of the effectiveness of a single circulating PAG concentration (d 31) to predict EM, a receiver-operating characteristic curve was generated to identify a PAG concentration on d 31 that would predict EM with $\geq 95 \%$ accuracy in cows that received TAI or TET. Based on positive and negative predicative value analysis, a circulating concentration of PAG below $1.4 \mathrm{ng} / \mathrm{mL}$ (TAI; minimal detectable level $0.28 \mathrm{ng} / \mathrm{mL}$ ) and $1.85 \mathrm{ng} / \mathrm{mL}$ (TET) was $95 \%$ accurate in predicting EM (between d 31 and 59) at d

\footnotetext{
Received July 31, 2015.

Accepted October 17, 2015.

${ }^{1}$ Present address: Department of Animal Science, The University of Tennessee, Knoxville.

${ }^{2}$ These authors contributed equally in the generation and preparation of this manuscript.

${ }^{3}$ Corresponding author: greenjo@missouri.edu
}

31 of gestation, respectively. Following TET, embryonic loss was tracked by Doppler ultrasound, progesterone, and PAG from d 24 to 59 of gestation, with more than $50 \%$ of the loss occurring between d 31 and 38 of gestation. In summary, circulating concentrations of PAG on d 31 of gestation may provide a good marker for predicting EM between d 31 and 59 of gestation, and the data suggest that this model could help predict which cows will undergo late EM.

Key words: bovine pregnancy-associated glycoprotein, pregnancy loss

\section{INTRODUCTION}

The factors negatively affecting fertility in the lactating dairy cow are multifaceted; however, it is well documented that embryonic mortality (EM) during the first third of gestation plays a large part in reproductive inefficiency. Intensive genetic selection over the past few years has emphasized both milk production and fertility. This increased selection pressure on fertility has led to a notable increase in reproductive success in dairy cows but has not eliminated the embryonic wastage that occurs during early gestation. Multiple reports have demonstrated that early EM $(<28 \mathrm{~d}$ of gestation) accounts for a large amount of the loss that occurs during gestation (DeJarnette et al., 1992; Dalton et al., 2001; Sartori et al., 2002). Loss of pregnancies after d 28 represents a smaller proportion of EM. However, the economic consequences of late EM ( $>28 \mathrm{~d}$ of gestation) are reported to be disproportionately greater than that of early EM, because late EM can cause a significant delay in conception date (Silke et al., 2002). In cattle, late EM has been reported to range from 3.2 to $42.7 \%$ (Vasconcelos et al., 1997; Cartmill et al., 2001a,b; Lamb, 2002; Ribeiro et al., 2011; Ribeiro et al., 2012; Aono et al., 2013; Pereira et al., 2013; Ribeiro et al., 2013); however, little is known about the exact causes of these losses. The timing of this loss between d 30 to 60 of gestation suggests compromised placental function because the timing corresponds to when estab- 
lishment of a functional cotyledonary placenta in cattle is taking place (e.g., between d 25 and 40; Pfarrer et al., 2006; Aires et al., 2014).

Because placental insufficiency is a potential cause of late EM, identification of a marker of placental function in the maternal circulation may be a useful tool for predicting late EM. Bovine pregnancy-associated glycoproteins (PAG) are secreted by the ruminant placenta (Wallace et al., 2015) into the maternal circulation starting about d 24 of gestation and have been used to diagnose pregnancy in cattle (Sasser et al., 1986; Zoli et al., 1992; Green et al., 2005) and may serve as a marker of placental function (Perry et al., 2005; Breukelman et al., 2012; Pohler et al., 2013). The objectives of these experiments were to examine the relationship between d-31 circulating concentrations of PAG and embryonic survivability in lactating dairy cows undergoing timed AI (TAI) or timed embryo transfer (TET), along with determining when the majority of late EM is occurring during gestation.

\section{MATERIALS AND METHODS}

All animal procedures followed the recommendations of the Guide for the Care and Use of Agricultural Animals in Agricultural Research and Teaching (FASS, 1999). Cows that were past the voluntary waiting period (40 d) and not pregnant received the following protocol: an intravaginal progesterone (P4) insert containing $1.9 \mathrm{~g}$ of P4 (Zoetis, São Paulo, Brazil) and $2.0 \mathrm{mg}$ (i.m.) of estradiol benzoate $(2.0 \mathrm{~mL}$ of Estrogin, Farmavet, São Paulo, SP, Brazil) on day -11, $25 \mathrm{mg}$ (i.m.) of dinoprost (PGF; $5.0 \mathrm{~mL}$ of Lutalyse, Zoetis) on day -4 , intravaginal-P4-insert withdrawal and $1.0 \mathrm{mg}$ (i.m.) of estradiol cypionate (0.5 mL of E.C.P., Zoetis) on day -2 , and fixed TAI on d 0 (study 1 ) or TET on $\mathrm{d} 7$ (study 2 and 3 ). In study 1 and 2 only pregnant cows at d 31 were used, based on presence of a viable embryo (presence of a heartbeat) detected by ultrasound scan. In study 3 only pregnant cows were used, based on the presence of a vascularized corpus luteum (CL) at d 24 of gestation, evaluated with a color Doppler ultrasound, an increased circulating concentration of $\mathrm{P} 4$ on d $24(>1.0 \mathrm{ng} / \mathrm{mL})$, and circulating d-24 PAG greater than the baseline of the assay.

\section{Experiment 1-TAI}

Timed AI was performed (d 0) by using commercial frozen-thawed semen from 13 different sires. This study used a total of 490 pregnant lactating Holstein cows. At the beginning of the experiment $(\mathrm{d}-11)$, cows averaged $147 \pm 4.19$ DIM, yielded $29.5 \pm 0.3 \mathrm{~kg}$ of milk per day, and had a BCS of $2.84 \pm 0.02$ [in a 1 (emaciated) to 5 (obese) scale (Wildman et al., 1982)]; 264 were primiparous $(=1)$; 209 were multiparous $(\geq 2)$; and cows had been bred $1.96 \pm 0.11$ times.

\section{Experiment 2-TET}

Timed embryo transfer was performed (d 7) by using fresh embryos produced in vitro from 76 donors and commercial frozen-thawed sexed semen (X-bearing sperm) from 9 sires. This study used a total of 285 pregnant lactating Girolando cows ( $\sim$ three-quarters Holstein-Bos taurus $\times$ Bos indicus). At the beginning of the experiment $(\mathrm{d}-11)$, cows averaged $135 \pm 4.9$ DIM, yielded $18.9 \pm 0.4 \mathrm{~kg}$ of milk per day, and had a BCS of $2.86 \pm 0.03$ [in a 1 (emaciated) to 5 (obese) scale (Wildman et al., 1982)]; 90 were primiparous (= 1); 148 were multiparous $(\geq 2)$, and cows had been bred $2.07 \pm 0.15$ times.

\section{Experiment 3-Profiling of Embryonic Loss Following TET}

The TET was performed (d 7) by using fresh embryos produced in vitro from 24 donors and commercial frozen-thawed sexed semen (X-bearing sperm) from 8 sires. This study used a total of 101 pregnant lactating Girolando cows. At the beginning of the experiment (d -11 ), cows averaged $109 \pm 10.6$ DIM, yielded $22.9 \pm$ $0.8 \mathrm{~kg}$ of milk per day, and had a BCS of $3.08 \pm 0.04$ [in a 1 (emaciated) to 5 (obese) scale (Wildman et al., 1982)]; 50 were primiparous $(=1)$; 51 were multiparous $(\geq 2)$; and cows had received an embryo $2.27 \pm 0.18$ times.

\section{Transrectal Ultrasonography}

The uteri of all cows in experiments 1 and 2 were examined on d 31 of gestation following TAI or TET and at d 59 of gestation to determine pregnancy status (viable fetal heartbeat) and incidence of late embryonic or fetal mortality. In experiment 3, cows were examined by ultrasonography on d 24 by using a Doppler ultrasound probe to determine blood flow to the CL. Cows were considered to be pregnant on d 24 if they met the following criteria: (1) a well-vascularized CL, as detected by ultrasound, on the same ovary that possessed a CL at the time of embryo transfer, (2) increased circulating concentrations of P4 (>1.0 ng/mL) on d 24, and (3) the presence of elevated d-24 PAG. Normal transrectal ultrasonography as explained above was conducted on d $31,38,45,52$, and 59 of gestation in all cows. Only cows bearing singletons were used in this study. 


\section{Blood Collections}

All cows were bled at the time of ultrasound based on the above time points. All samples were harvested by venipuncture into a $10-\mathrm{mL}$ vacutainer tube and allowed to clot at room temperature for $1 \mathrm{~h}$ before being placed in a $4^{\circ} \mathrm{C}$ refrigerator for $24 \mathrm{~h}$. Following centrifugation at $3,000 \times g$ for $20 \mathrm{~min}$ at $4^{\circ} \mathrm{C}$, serum was collected and stored at $-20^{\circ} \mathrm{C}$ until measurement of $\mathrm{P} 4$ and PAG as described below.

\section{Assays}

Serum concentrations of $\mathrm{P} 4$ were quantified by RIA with the Coat-A-Count RIA kit (Diagnostic Products Corporation, Los Angeles, CA) as described previously (Bellow et al., 1991; Kirby et al., 1997). Intraassay coefficient of variation was $5 \%$, and the assay sensitivity was $0.08 \mathrm{ng} / \mathrm{mL}$ for the P4 RIA. In addition, a replicate analysis of these same samples for serum concentrations of $\mathrm{P} 4$ was performed, for the purpose of establishing and validating a new P4 RIA, due to the fact that the P4 Coat-A-Count RIA kit assay is no longer commercially available. This replicate analysis was performed using the liquid-liquid phase double-antibody precipitation assay reagents supplied by MpBio (cat\# 07-170105; Santa Ana, CA). Concentrations of $\mathrm{P} 4$ were determined in triplicate $100-\mu \mathrm{L}$ aliquots of serum using a nonextracted, competitive, liquid-liquid phase, double-antibody RIA procedure according to the general manufacturer recommendations (MpBio cat\# 07-170105), with additional assay procedures and validation information as follows. Standard concentrations of $\mathrm{P} 4(0.005,0.01,0.02,0.05,1.0,2.5$, and $5 \mathrm{ng}$ per tube; using either standards supplied by the manufacturer or formulated from powdered P4) and increasing volumes of serum $(25,40,60$, and 100 $\mu \mathrm{L}$ ) from a bovine P4 serum pool were added to assay tubes in triplicate and the total volume balanced to $100 \mu \mathrm{L}$ per tube with buffer consisting of $0.1 \%$ gelatin, $0.01 M$ EDTA, $0.9 \% \mathrm{NaCl}, 0.01 M \mathrm{PO}_{4}, 0.01 \%$ sodium azide, and $0.05 \%$ Tween-20, $\mathrm{pH}=7.1$ (PABET). Rabbit anti-progesterone primary antiserum $(200 \mu \mathrm{L}$; MpBio cat\# 07-170105) was then added to each tube, excluding total and nonspecific binding tubes. Immediately thereafter, $100 \mu \mathrm{L}$ of ${ }^{125} \mathrm{I}$-progesterone (MpBio cat\# 07-170105) was added to all tubes and incubated at $37^{\circ} \mathrm{C}$ for $1 \mathrm{~h}$. The antigen-antibody complex was then precipitated following a $15 \mathrm{~min}, 22^{\circ} \mathrm{C}$ incubation with $100 \mu \mathrm{L}$ of a precipitated sheep-anti-rabbit second antiserum by centrifugation at $3,750 \times g$ for $30 \mathrm{~min}$ at $4^{\circ} \mathrm{C}$, and the supernatant was discarded by aspiration. Assay tubes containing the precipitated antigen $-1^{\circ}$ antibody complex were counted for $1 \mathrm{~min}$ on a LKB1277 gamma counter (LKB Wallac, Turku, Finland). Standards and pooled aliquots of serum were linear $(\log / \operatorname{logit}-$ transformation; $\mathrm{R}^{2}>0.99$ ) and parallel over a mass of 0.005 to $5 \mathrm{ng}$ per tube and a serum volume of 25 to $100 \mu \mathrm{L}$, respectively. Total specific binding averaged $40 \%$, and the minimum detectable concentration was $0.005 \mathrm{ng} /$ tube. Moreover, estimates of the percentage of recovered mass of $\mathrm{P} 4$ from petroleum ether extracts of standards, nonextracted samples, and serial dilutions of bovine P4 pool were $>99 \%$. Inter- and intraassay estimates of coefficients of variation were $<5 \%$.

Serum concentrations of PAG were measured using 2 PAG ELISA. One was a sandwich ELISA similar to that described by Green et al. (2005). It is identical to the assay employed by Pohler et al. (2013), and it differs from the PAG assay described in Green et al. (2005) by employing a different polyclonal antibody (Ab45) to detect the complex between the PAG monoclonal antibodies and the PAG itself. The second PAG assay was a commercial test from Idexx Laboratories Inc. (Westbrook, ME). Each test plate was run with a standard curve, a pooled sample collected from a pregnant cow at d 60 of gestation, and a pooled sample from a nonpregnant cow. Because the PAG ELISA described by Green et al. (2005) is an in-house assay, we felt it was important to analyze the samples in parallel with a commercial PAG ELISA.

\section{Statistical Analysis}

One-way ANOVA (SAS 9.4; SAS Institute Inc., Cary, $\mathrm{NC}$ ) was used to test differences among circulating concentrations of PAG on d 31 for lactating dairy cows that maintained the pregnancy or subsequently exhibited pregnancy failure. The LOGISTIC procedure in SAS (9.4) was used to determine the probability of pregnancy maintenance based on circulating PAG measured on d-31 sera. Receiver operating characteristic (ROC) curves were generated in the MedCalc software package (MedCalc Software, Oostende, Belgium), setting EM as the true positive. Following the generation of ROC curves, the resulting true positives and false positives were subjected to positive and negative predictive value analysis to determine a concentration of PAG on d 31 below which $95 \%$ of cows would experience embryonic loss by d 59. Sire or donor had no significant effect in any experiment on circulating concentrations of PAG; therefore, these were not included in the models. The PROC MIXED was used in experiment 3 to identify differences in concentrations of PAG and P4. For all simple correlations, PROC CORR was used in the SAS (9.4) program. 


\section{RESULTS}

\section{Experiment 1-TAI}

Mean circulating concentration of PAG (determined by the Ab45 assay) at $\mathrm{d} 31$ of gestation for all pregnant cows was $9.50 \pm 5.33 \mathrm{ng} / \mathrm{mL}$ (mean $\pm \mathrm{SD}$; range 0.11 to $31.83 \mathrm{ng} / \mathrm{mL}$; TAI-maintained $\mathrm{n}=413$; TAI-EM $\mathrm{n}$ $=77$ ). Only pregnant cows were included in the data analysis. On d 31 of gestation 490 cows were confirmed pregnant by transrectal ultrasonography, and by d 59 of gestation 49 cows had undergone late EM (12\%) followed by an additional 28 cows losing a pregnancy between d 59 and parturition (19\%). Mean serum concentrations of PAG at $\mathrm{d} 31$ of gestation in cows that maintained pregnancy until d 59 were significantly higher $(9.58 \pm 0.31$; mean \pm SEM; $P<0.05$; Figure 1a) than those of cows that did not maintain pregnancy $(4.15 \pm 0.33$; mean \pm SEM $)$ from d 31 to 59 of gestation. No relationship existed between PAG concentration on d 31 and pregnancy loss that took place between d 59 and parturition. Circulating concentration of PAG on d 31 was included as a continuous variable in a logistical regression of EM occurring between d 31 and 59 of gestation. The preceding analysis showed that as PAG concentration on d 31 decreased, the likelihood of EM by d 59 of gestation increased $(P<0.05$; Figure 1 b) but not between $\mathrm{d} 59$ and parturition.

An ROC curve was used to characterize the accuracy of detecting late EM between d 31 and 59 of gestation and had an area under the curve of $82.3 \%(P<0.05$; Figure 2), whereas the area under the curve associated with predicting EM between d 31 and parturition was $67.1 \%$. An area under the curve above $50 \%$ denotes the ability to distinguish $(P<0.05)$ between the 2 populations. Based on positive and negative predicative value analysis, a circulating concentration of PAG below 1.4 $\mathrm{ng} / \mathrm{mL}$ was $95 \%$ accurate (accuracy $=$ correct number diagnosed based on cutoff value/number of cattle below cutoff value $\times 100)$ in predicting EM between d 31 and 59 of gestation. Applying this cutoff value, 20 cows would have been predicted to undergo EM, of which 19 did undergo EM between d 31 and 59 of gestation. No correlation existed between PAG concentrations on d 31 of gestation from the PAG Ab45 assay and the commercial Idexx PAG assay (Figure 2). Using d 31 serum concentrations as detected by the Idexx assay, no significant relationship existed between circulating PAG and late EM.

\section{Experiment 2-TET}

For animals that underwent TET, the mean circulating concentration of PAG (determined by the Ab45 as- say) at d 31 of gestation for all pregnant cows was 8.32 $\pm 5.65 \mathrm{ng} / \mathrm{mL}$ (mean $\pm \mathrm{SD}$; range 0.13 to $40.68 \mathrm{ng} /$ $\mathrm{mL}$; TET-maintained $\mathrm{n}=238$; TET-EM $\mathrm{n}=47$ ). On d 31 of gestation 285 cows were confirmed pregnant by transrectal ultrasonography, and by d 59 of gestation 47 cows had undergone late EM (20\%). Mean serum concentrations of PAG at d 31 of gestation between cows that established and maintained a pregnancy until d 59 were significantly higher $(8.61 \pm 1.53$; mean \pm SEM; $P<0.05$; Figure 3a) compared with cows that established and did not maintain a pregnancy (3.78 \pm 0.58 ; mean \pm SEM) until d 59 of gestation. Circulating concentrations of PAG on d 31 were included as a continuous variable in a logistical regression of EM until d 59 of gestation; as d-31 PAG decreased, the likelihood of EM by d 59 of gestation increased $(P<$ 0.05; Figure $3 \mathrm{~b}$ ). After calculating an ROC curve, EM between $\mathrm{d} 31$ and 59 of gestation had an area under the curve of $77.9 \%(P<0.05$; Figure 4$)$. Based on positive and negative predicative value analysis, a circulating concentration of PAG below $1.85 \mathrm{ng} / \mathrm{mL}$ was $95 \%$ accurate in predicting EM. Applying this cutoff, 21 cows would have been predicted to undergo EM, of which 20 did undergo EM between d 31 and 59 of gestation. The correlation between PAG concentrations on d 31 of gestation from the Ab45 assay and commercial assay was $\mathrm{r}=0.64(P<0.05)$. Using d-31 serum concentrations, there was a significant relationship between circulating PAG and late EM using the Idexx PAG assay. A serum concentration on d 31 of PAG below $1.4 \mathrm{ng} / \mathrm{mL}$ resulted in a $95 \%$ confidence estimate that EM would occur between d 31 to 59 of gestation, with an area under the curve of $77.1(P<0.05$; Figure 4$)$.

\section{Experiment 3-Profiling of Embryonic Loss Following TET}

On d 24 of gestation, 101 cows that underwent TET were determined pregnant based on the presence of a vascularized CL at d 24 of gestation, evaluated with a color Doppler ultrasound, increased circulating concentrations of $\mathrm{P} 4(>1.0 \mathrm{ng} / \mathrm{mL})$ on d 24 , and the presence of elevated d-24 PAG (Figure 5a). The cows were retested for pregnancy status on d 31 by ultrasound. Of the 101 animals that were pregnant on d 24, 80 animals were still pregnant on d 31. Based on the qualifications for pregnancy status on d 24 of gestation, 21 (20.8\%) animals experienced EM between d 24 and 31 of gestation. On d 24 of gestation, PAG concentration in the pregnant cows $(3.06 \pm 0.49 \mathrm{ng} / \mathrm{mL}$; mean \pm SEM) was significantly increased $(P<0.05)$ in circulation compared with nonpregnant cows $(0.94 \pm 0.16$ $\mathrm{ng} / \mathrm{mL}$; mean $\pm \mathrm{SEM}$ ) based on the $\mathrm{d}-31$ pregnancy diagnosis. In addition $\mathrm{P} 4$ concentrations were not 
statistically different $(P>0.05)$ on $\mathrm{d} 24$ of gestation between cows that remained pregnant $(7.52 \pm 0.37 \mathrm{ng} /$ $\mathrm{mL}$; mean $\pm \mathrm{SEM})$ on $\mathrm{d} 31$ compared with those that were not pregnant $(4.95 \pm 3.76 \mathrm{ng} / \mathrm{mL}$; mean $\pm \mathrm{SEM})$ but were considered pregnant by Doppler ultrasound on d 24 of gestation. However, the cows determined to be not pregnant on d 31 had a $34 \%$ decrease in $\mathrm{P} 4$ at d 24 compared with animals that were pregnant, suggesting 2 different physiological states between these cows. Progesterone assays were conducted using the traditional Coat-A-Count RIA and replicated using a liquid-liquid phase double-antibody precipitation assay supplied by MpBio. The data presented in the results are from the Coat-A-Count RIA; however, the results are highly correlated between the 2 assays $(\mathrm{r}=0.88 ; P$ $<0.05)$ across all samples.

On d 31 of gestation the maternal PAG concentration in all pregnant cows $(\mathrm{n}=80)$ was $9.06 \pm 4.48$ $\mathrm{ng} / \mathrm{mL}$ (mean $\pm \mathrm{SD}$; range 1.06 to $23.85 \mathrm{ng} / \mathrm{mL}$ ) and $\mathrm{P} 4$ was $8.01 \pm 4.61 \mathrm{ng} / \mathrm{mL}$ (mean $\pm \mathrm{SD}$; range 1.70 to $15.90 \mathrm{ng} / \mathrm{mL}$ ). No relationship existed between circulating concentrations of $\mathrm{P} 4$ on d 24 or 31 in cows that experienced EM between d 31 and 59; however, there was a significant $(P<0.05)$ relationship between late EM and d-31 PAG concentrations, which was also observed in experiments 1 and 2. The majority of EM

A

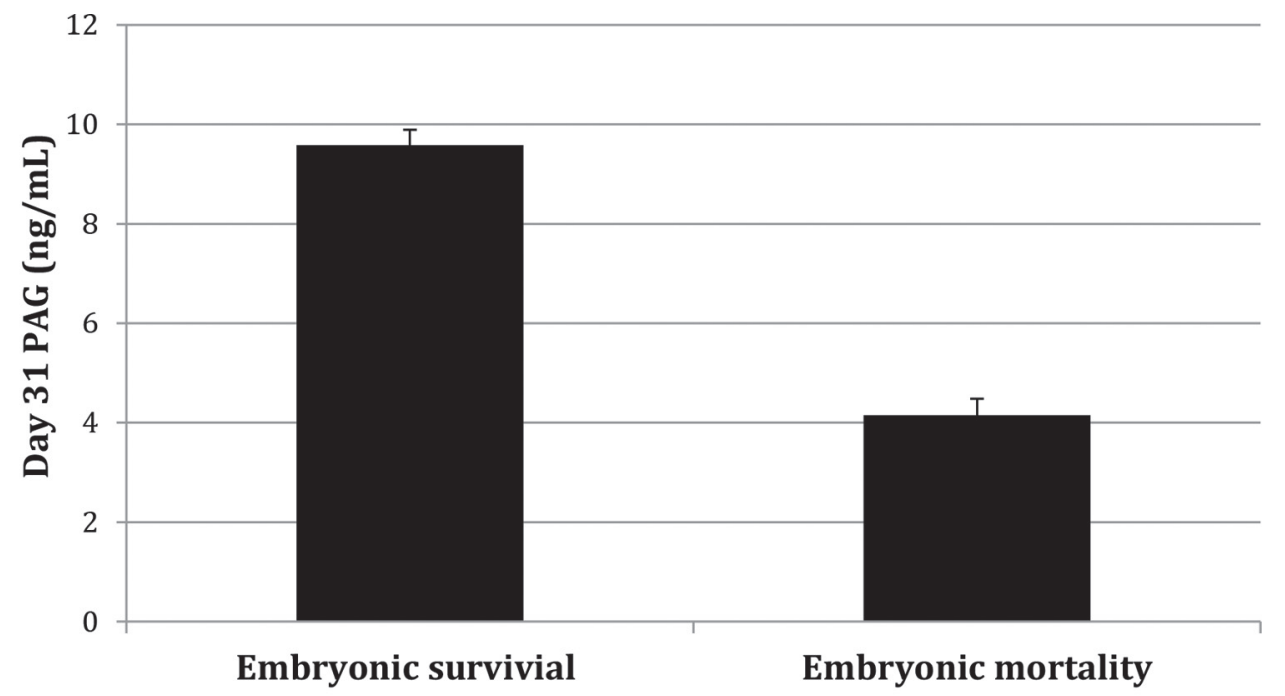

B

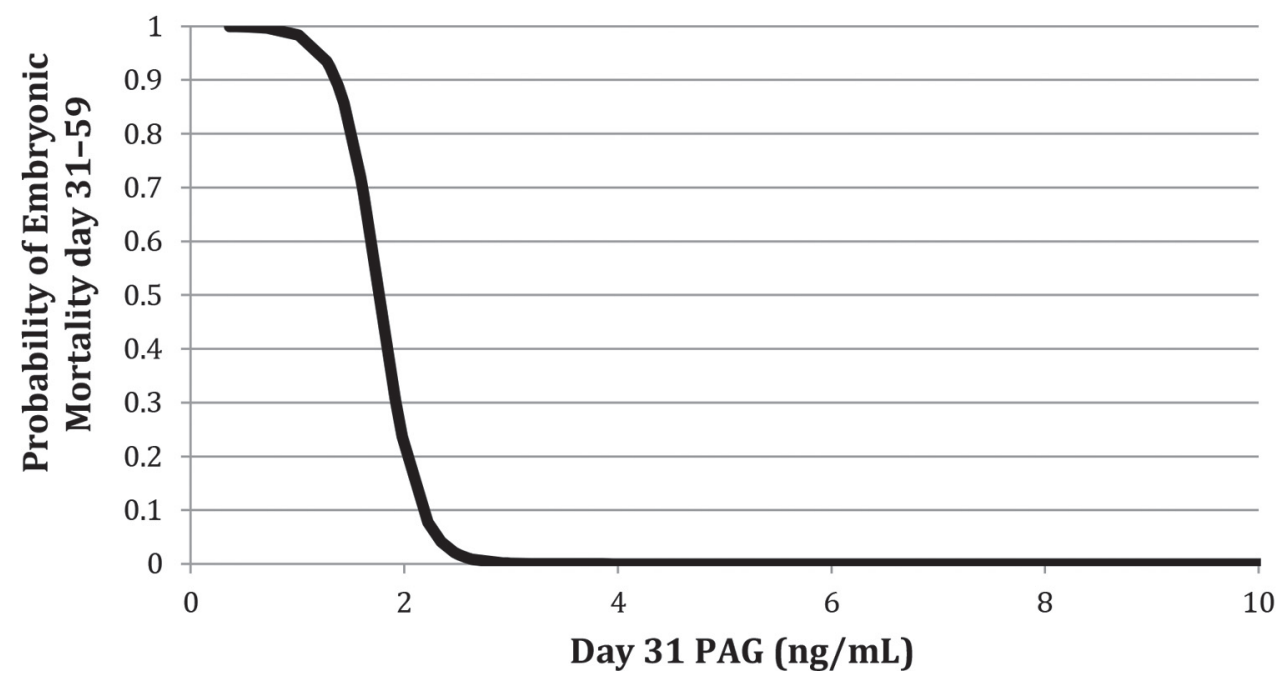

Figure 1. (A) Serum concentrations of pregnancy-associated glycoproteins (PAG; mean \pm SEM) in lactating dairy cows that received timed AI (TAI) on d 0 and had a viable embryo on d 31 of gestation $(\mathrm{n}=413)$ and either maintained (embryonic survival; $\mathrm{n}=364)$ or experienced embryonic mortality $(\mathrm{n}=49)$. Dairy cows that experienced late embryonic mortality by d 59 of gestation had decreased $(P<0.05)$ circulating concentrations of PAG on d 31 compared with cows that maintained an embryo until d 59. (B) Probability of late embryonic mortality following TAI between d 31 and 59 of gestation based on d-31 serum concentrations of PAG $(n=413)$. Decreased serum concentrations of PAG on d 31 significantly increased $(P<0.05)$ the probability of late embryonic mortality in lactating dairy cows following TAI. 


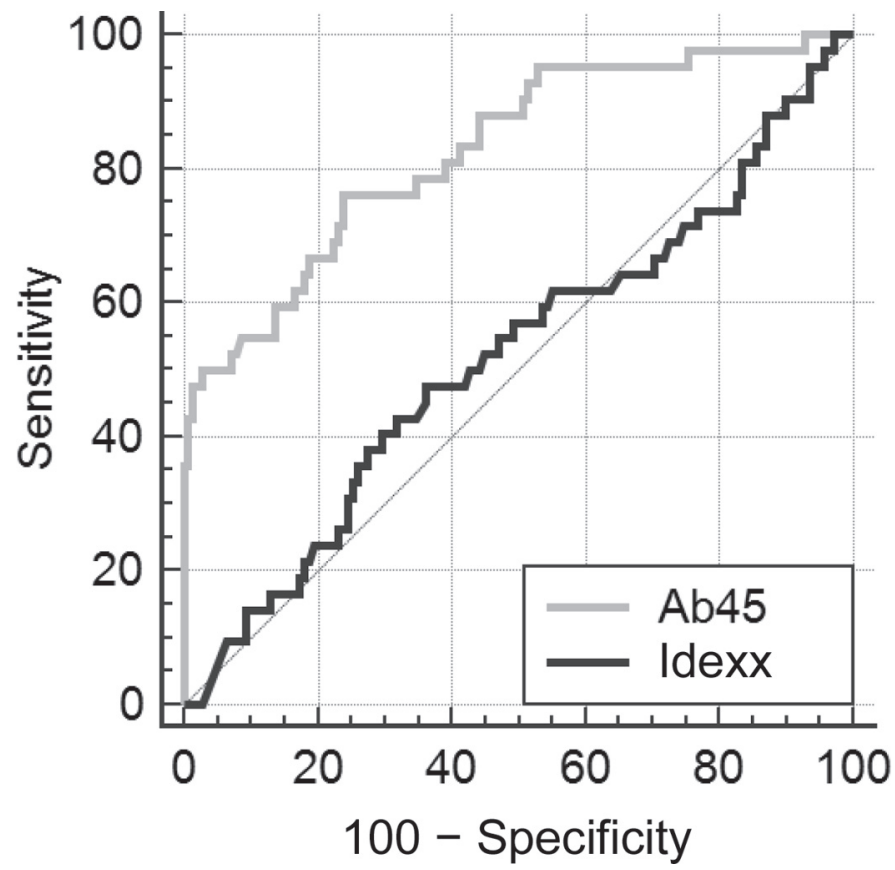

Figure 2. Receiver operating curve using d-31 circulating concentrations of pregnancy-associated glycoproteins (PAG) determined by 2 assays, Ab45 and Idexx (Idexx Laboratories Inc., Westbrook, ME), to model embryonic mortality between d 31 and 60 of gestation in lactating dairy cows following timed AI. Using the Ab45 assay a serum concentration of PAG below $1.4 \mathrm{ng} / \mathrm{mL}$ resulted in a $95 \%$ confidence that embryonic mortality would occur between d 31 and 59 of gestation, with an area under the curve of $82.3(P<0.05)$. However, using the Idexx assay no significant relationship was identified, providing no confidence as a test. The receiver operating characteristic curve graphically displays the relationship between true-positive rate (sensitivity) and false-positive rate (100 - specificity) when an increasing cutoff for the PAG test was applied. When the true-positive rate and the falsepositive rate both decrease as the cutoff value is increased, this results in a diagonal line through the center meaning the test is not predictive (50:50 probability). However, when the line is deflected to the left of center, the test is useful because it has a relatively high true-positive rate and a low false-positive rate at a specific cutoff.

after d 31 occurred between d 31 and $38(\mathrm{n}=8 ; 54 \%$; Figure $5 \mathrm{~b})$, followed by d 38 and $45(\mathrm{n}=6 ; 40 \%)$ and d 45 to $59(\mathrm{n}=1 ; 6 \%)$.

\section{DISCUSSION}

Early pregnancy diagnosis is a critical part of successful reproductive management practices and has traditionally been conducted by using either transrectal palpation or ultrasonography. However with the limited availability of skilled practitioners and the demand for easier and more accurate diagnosis, chemical pregnancy detection in cattle has become common practice (Silva et al., 2007; Romano and Larson, 2010; Leblanc, 2013; Gajewski et al., 2014; Lawson et al., 2014). Over the past $30 \mathrm{yr}$ multiple reports have been published describing the detection of PAG in the maternal circula- tion and milk to successfully detect pregnancy in several ruminant species (Sasser et al., 1986; Sousa et al., 2006; Szafranska et al., 2006). In addition, decreased circulating maternal concentrations of PAG in ruminants that experienced late EM have been reported in dairy (Humblot et al., 1988; Breukelman et al., 2012) and beef cattle (Perry et al., 2005; Pohler et al., 2013), along with sheep (Wallace et al., 1997).

Late EM is one of the primary factors that reduce reproductive efficiency, and the economic consequences of late EM are significant because of a prolonged delay in conception date (Silke et al., 2002). Late EM in cattle has ranged from 3.2 to $42.7 \%$ depending on the type of cattle, environment, and whether the embryo was produced in vivo or in vitro (Vasconcelos et al., 1997; Cartmill et al., 2001a,b; Lamb, 2002). In the current study, late EM ranged from 18.6 to $19.75 \%$ with an average of $19 \%$ in all experiments. The majority of these losses were shown to occur between d 31 and 59 of gestation in experiment 1 with TAI, and more than $50 \%$ occurred between d 31 and 38 , with $94 \%$ occurring between d 31 and 45 in experiment 3 using TET. These data are in agreement with previously published results suggesting that about half of late EM occurs between d 28 and 42 of gestation (52\%, Vasconcelos et al., 1997; $47.5 \%$, Silke et al., 2002). Importantly, this time period coincides with placentation, which is accompanied by extensive endometrial and trophoblast tissue remodeling (Assis Neto et al., 2010; Aires et al., 2014) and a dramatic increase in circulating concentrations of prostaglandins $\mathrm{E}, \mathrm{F}$, and $\mathrm{I}$ in the utero-ovarian vein (Schallenberger et al., 1989).

Development of management strategies to decrease late EM requires the identification of an accurate predictor of late EM, and the data in this study indicate that maternal circulating concentrations of PAG may be a candidate. Pohler et al. (2013) reported that following embryo transfer on $\mathrm{d} 7$, beef cows that experienced EM between d 28 and 72 of gestation had decreased concentrations of PAG on d 28 compared with cows that maintained a pregnancy. Those authors suggested that the concentration of d-28 PAG may be a useful predictor of future EM during early gestation. Similar results have also been shown in beef cattle undergoing TAI (Perry et al., 2005). In dairy cattle, a similar relationship between circulating concentration of PAG and pregnancy maintenance has been reported but not investigated in detail (Humblot et al., 1988; Thompson et al., 2010; Breukelman et al., 2012). However, no relationship has also been reported between circulating concentrations of PAG early in pregnancy (d 28 to 32 ) and embryonic survivability in dairy cattle (Ricci et al., 2015). Based on the positive relationship between d-31 circulating concentrations of PAG and embryonic 
survivability in cows from the present study, it seems likely that PAG may be useful as circulating biomarkers that can be used to identify pregnant (or open) animals and to provide insight into the likelihood of pregnancy maintenance beyond d 31 of gestation.

In addition to PAG, the association between circulating concentrations of $\mathrm{P} 4$ and the incidence of late EM has been examined. Breukelman et al. (2012) demonstrated that circulating $\mathrm{P} 4$ before or after embryo transfer was not associated with late EM mortality, but circulating concentrations of pregnancy-associated glycoprotein 1 (PSPB or PAG1) were positively associated with embryonic survivability. In the current study, no relationship existed between circulating P4 concentrations and EM or survivability, which is in agreement with some previous reports (Breukelman et al., 2012; Pohler et al., 2013) but not the report of Starbuck et al. (2004) in which an association between P4 concentrations at wk 5 of gestation in lactating dairy cows and embryonic survivability was reported. These results may not be surprising, however, based on the fact that $\mathrm{P} 4$ is an indirect measure of pregnancy status and PAG is a direct measure in that it is pregnancy specific (i.e., derived from the placenta itself). Pohler et al. (2013)

A

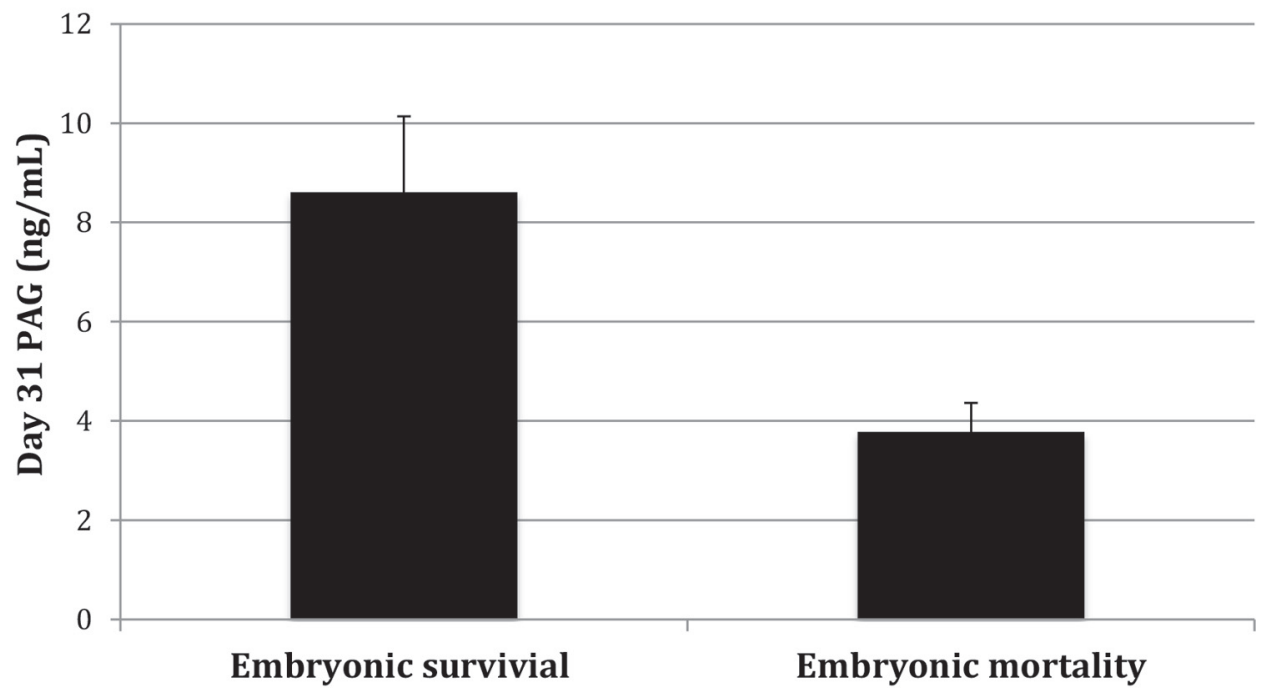

B

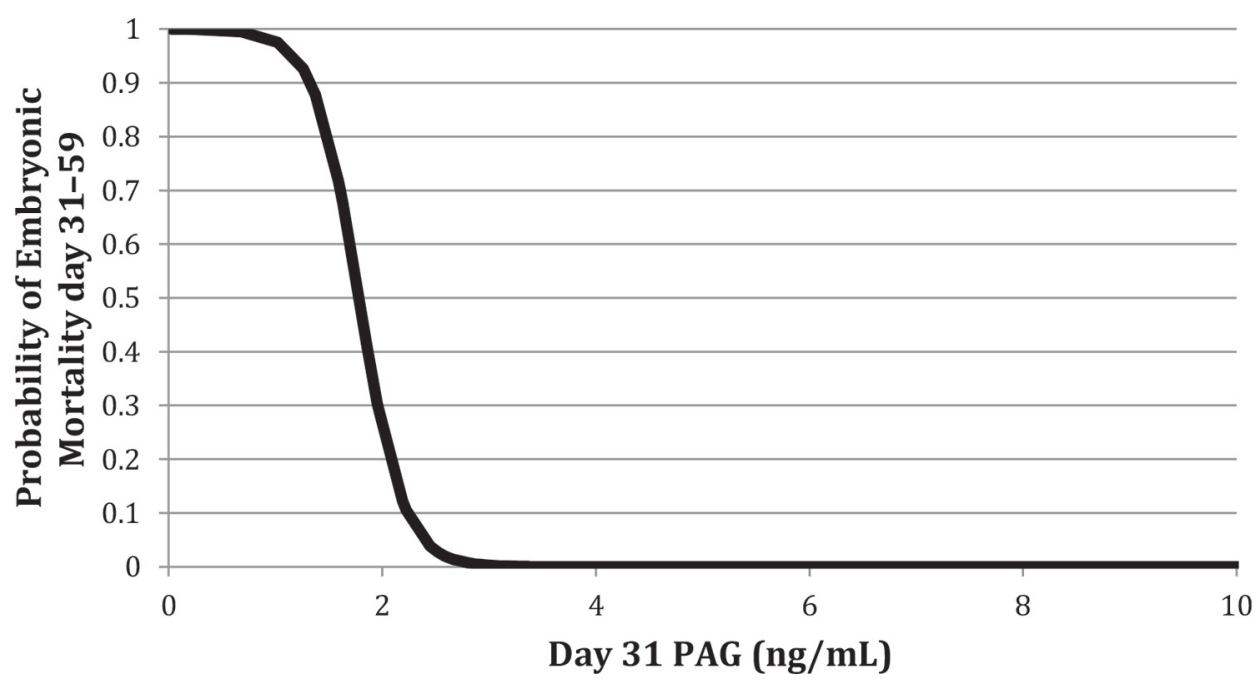

Figure 3. (A) Serum concentrations of pregnancy-associated glycoproteins (PAG; mean \pm SEM) in lactating dairy cows that received timed embryo transfer (TET) on d 7 and had a viable embryo on $\mathrm{d} 31$ of gestation $(\mathrm{n}=285)$ and either maintained (embryonic survival; $\mathrm{n}=238$ ) or experienced embryonic mortality $(\mathrm{n}=47)$. Dairy cows that experienced embryonic mortality by d 59 of gestation had decreased $(P<0.05)$ circulating concentrations of PAG on d 31 compared with cows that maintained an embryo until d 59. (B) Probability of late embryonic mortality following TET between d 31 and 59 of gestation based on d-31 serum concentrations of PAG $(\mathrm{n}=238)$. Decreased serum concentrations of PAG on d 31 significantly increased $(P<0.05)$ the probability of late embryonic mortality in lactating dairy cows following TET. 


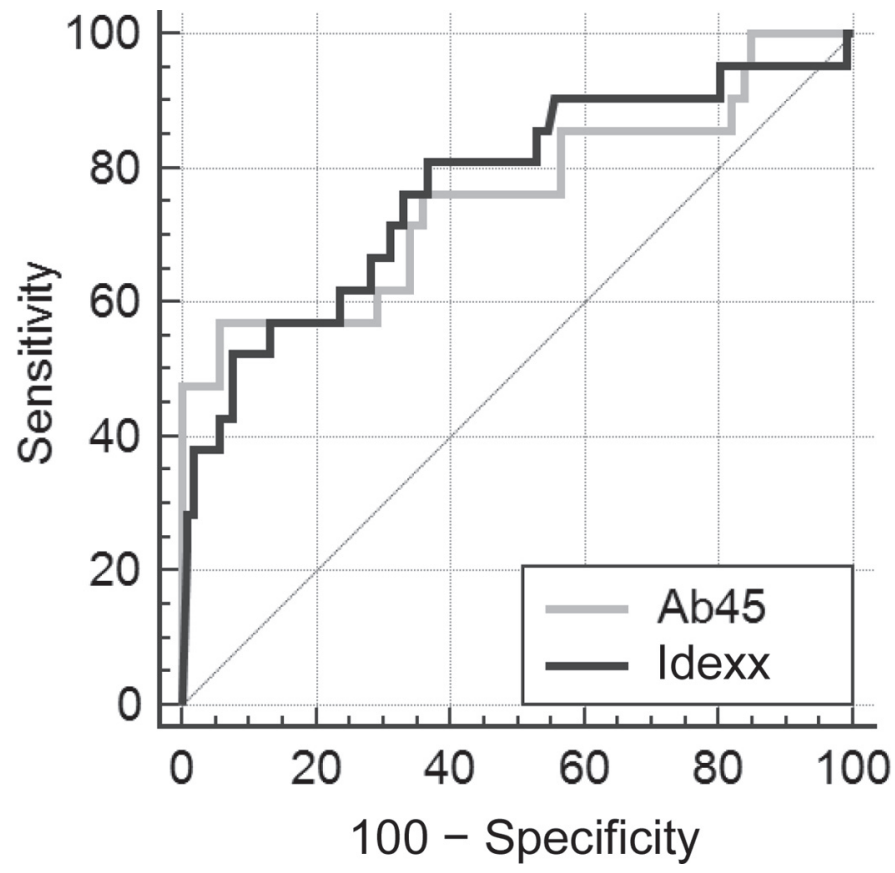

Figure 4. Receiver operating curve using d-31 circulating concentrations of pregnancy-associated glycoproteins (PAG) determined by 2 assays, Ab45 and Idexx (Idexx Laboratories Inc., Westbrook, ME), to model embryonic mortality between d 31 and 59 of gestation in lactating dairy cows following timed embryo transfer. Using the Ab45 assay a serum concentration of PAG below $1.8 \mathrm{ng} / \mathrm{mL}$ resulted in a $95 \%$ confidence that embryonic mortality would occur between $\mathrm{d} 31$ and 59 of gestation with an area under the curve of $77.9(P<0.05)$. Using the Idexx assay a serum concentration of PAG below $1.425 \mathrm{ng} /$ $\mathrm{mL}$ resulted in a $95 \%$ confidence that embryonic mortality would occur between d 31 and 59 of gestation, with an area under the curve of $77.1(P<0.05)$. The receiver operating characteristic curve graphically displays the relationship between true-positive rate (sensitivity) and false-positive rate (100 - specificity) when an increasing cutoff for the PAG test was applied. When the true-positive rate and the falsepositive rate both decrease as the cutoff value is increased, this results in a diagonal line through the center meaning the test is not predictive (50:50 probability). However, when the line is deflected to the left of center, the test is useful because it has a relatively high true-positive rate and a low false-positive rate at a specific cutoff.

reported that maternal circulating concentrations of PAG decreased before or at the same time as circulating $\mathrm{P} 4$, indicating that the conceptus dies before initiation of luteolysis. These data thus suggest that late EM between d 31 and 59 of gestation is placental or fetal derived compared with a luteal deficiency.

Currently, 3 commercial PAG testing platforms are available for use: (1) BioPRYN (BioTracking LLC, Moscow, ID), (2) DG29 (Conception Animal Reproduction Technologies, Beaumount, QC, Canada), and (3) Idexx Bovine Pregnancy Test (Idexx Laboratories Inc.). All of these tests have been shown to be effective at diagnosing pregnancy around d 30 of gestation by detecting PAG in serum or plasma (Silva et al., 2007; Romano and Larson, 2010). In addition, Silva et al.
(2009) and Green et al. (2011) demonstrated the effectiveness of using the Idexx testing platform for successful resynchronization of dairy cattle that were detected as not being pregnant on d 28. More recently, Idexx Laboratories developed an assay platform for detection of PAG in milk samples. Reports have been numerous on the validity of this assay platform for detecting PAG in milk samples, and this method seems to be as effective as serum- or plasma-based systems for detecting PAG (Leblanc, 2013; Gajewski et al., 2014; Lawson et al., 2014).

Based on the preceding results with the commercial PAG testing platforms, we evaluated a subset of samples from both experiment 1 (TAI) and 2 (TET) in which we compared a commercial (Idexx) PAG testing platform with the Ab45 assay. To obtain quantitative data from a commercial qualitative PAG testing platform, we applied a known PAG standard that was also used in the Ab45 assay. The results were rather surprising in that the values generated by the 2 assays were not correlated for cows that received TAI. However, the 2 assays were significantly correlated when investigating pregnancies resulting from TET. These data are rather difficult to interpret, but they suggest that TET pregnancies may result in PAG release that is measurably different from TAI-derived pregnancies. Another possibility is that the genetic background of the cows could influence PAG production. It has been well documented (reviewed by Farin et al., 2006) that in vitro-produced embryos can result in either normal development, EM, or a variety of developmental issues. In other words, PAG secretion and production from TET-derived pregnancies may be altered or different than normal TAI or natural pregnancies. Cows that become pregnant following transfer of an embryo produced by somatic cell nuclear transfer had rather unusual circulating PAG profiles during gestation compared with cows that received a control embryo (Hill et al., 2000; Chavatte-Palmer et al., 2006; Constant et al., 2011).

Based on data in experiment 3, cows undergoing TET had increased PAG production on d 24 of gestation, which is not surprising based on the first significant increase of PAG in the maternal circulation occurs on d 24 of gestation following TAI (Pohler et al., 2013). However, in that particular study only about half of the pregnant cows had detectable levels of PAG on d 24 of gestation compared with the current study, in which all cows had detectable PAG on d 24 of gestation following TET. It is also possible that the simple influence of species (Bos taurus vs. Bos indicus) between experiments 1 and 2 is what resulted in a difference in assay results. Mercadante et al. (2013) reported subspecies differences in PAG production during early gestation when using the Ab45-assay platform. These data provide further 
support for the idea that subspecies differences may affect early gestation PAG profiles. Based on data in these current experiments along with other published reports, the period of late EM seems to be occurring most frequently between d 28 and 42 of gestation, which corresponds to the time of placentome formation in cattle (Aires et al., 2014). Because of the timing of
EM along with the decreased concentration of a placental product (PAG) in cows that experience late EM, we hypothesized that the losses are driven by placental incompetence. Along with the well-characterized timing of late EM (between d 31 and 59), there seems be a high instance of loss between d 24 and 31 of gestation following maternal recognition of pregnancy based on

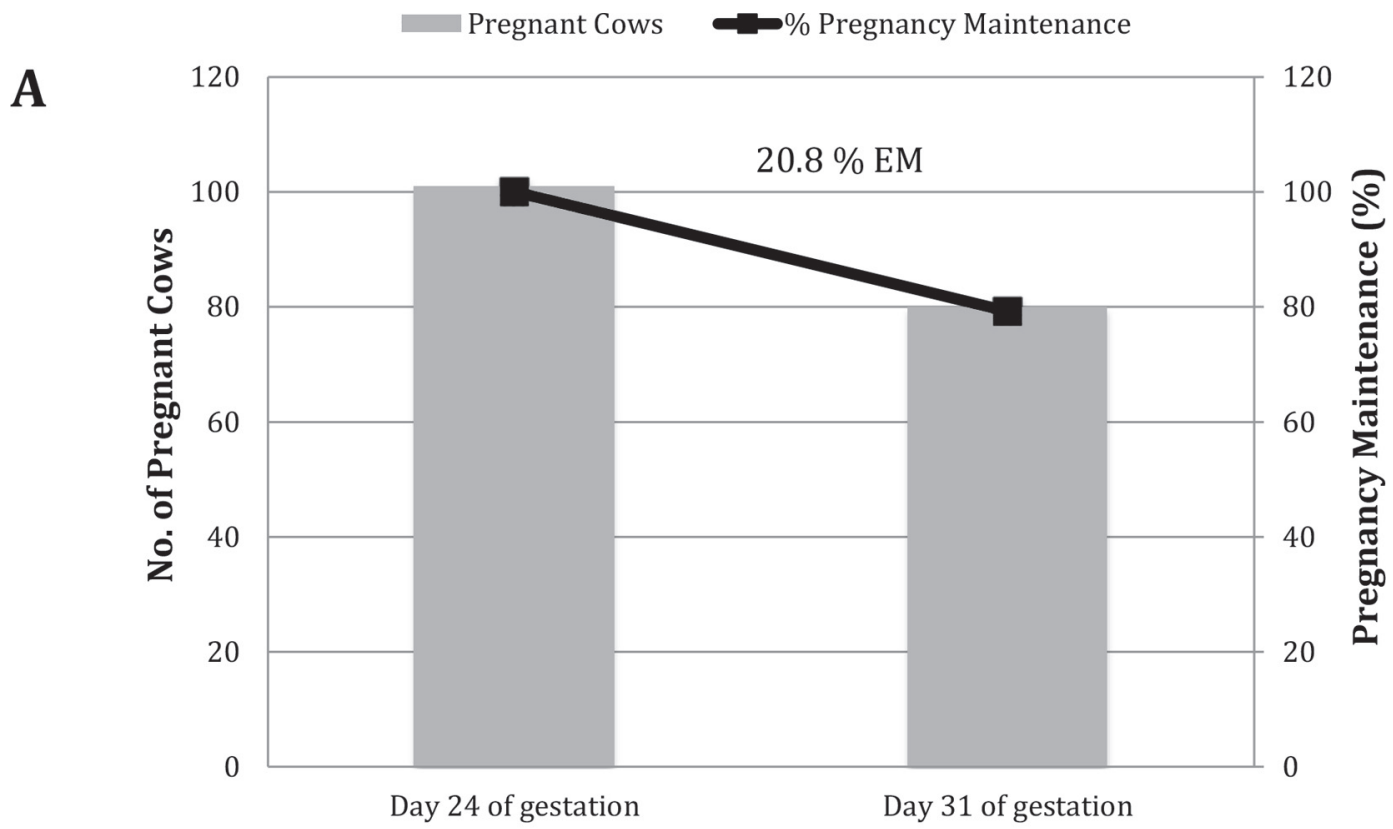

B

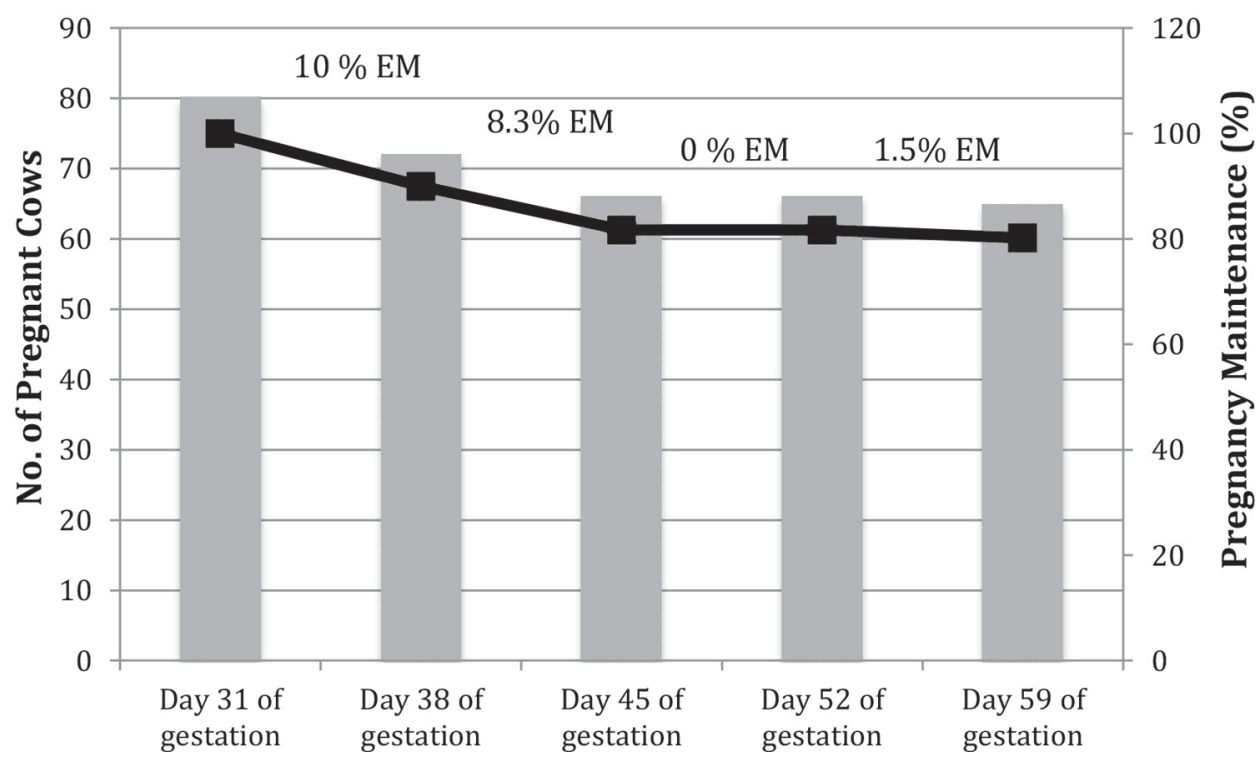

Figure 5. Pregnancy status following timed embryo transfer (TET) in lactating dairy cows. (A) On d 24 of gestation, 101 cows were diagnosed as pregnant based on a well-vascularized corpus luteum as detected by Doppler ultrasound on the same ovary that possessed a corpus luteum at the time of embryo transfer, increased circulating concentrations of progesterone $(>1.0 \mathrm{ng} / \mathrm{mL})$, and the presence of elevated pregnancy-associated glycoproteins; however, on d 31 only 80 cows had a viable embryo. Therefore, embryonic mortality (EM) following TET from d 24 until 31 was estimated to be $20.8 \%$. (B) On d 31 of gestation, 80 cows had a viable embryo detected by ultrasound. Embryonic mortality following TET in lactating dairy cows from d 31 until 59 of gestation was $19.8 \%$. The majority of EM after d 31 occurred between d 31 and 38 $(\mathrm{n}=8,10 \% ; 54 \%$ of the EM), followed by d 38 to $45(\mathrm{n}=6,8.3 \% ; 40 \%$ of the $\mathrm{EM})$ and $\mathrm{d} 45$ to $59(\mathrm{n}=1,1.5 \% ; 6 \%$ of the EM). 
the characterization of pregnancy on d 24 in this study. To completely understand these losses, further research is needed. Furthermore, it seems that no strong correlation exists between $\mathrm{P} 4$ and $\mathrm{EM}$, thus ruling out a luteal incompetence issue (Breukelman et al., 2012; Pohler et al., 2013). It also seems that ultrasound measurements of the embryo or fetus at $\mathrm{d} 35$ and 56 of gestation and PAG production are not related; however, it seems that embryonic or fetal size has a large amount of variation during this time period (Pohler et al., 2014). Taken together, our knowledge in the area of late EM is rather incomplete and further research is need to understand the biological causes of these losses.

\section{CONCLUSIONS}

In summary, a clear relationship exists between d 31 maternal PAG concentrations and embryonic survivability in lactating dairy cattle undergoing both TAI and TET. In the present study cows with d-31 PAG concentrations below 1.4 and $1.8 \mathrm{ng} / \mathrm{mL}$ (TAI and TET, respectively) resulted in a $95 \%$ chance of EM by d 60. Therefore, circulating PAG concentration at d 31 of gestation seems to be a potentially useful biomarker of late EM and a possible model to help dissect this period of pregnancy loss in cattle. As mentioned previously the exact mechanisms that cause late EM have been poorly examined based on the lack of a viable model for investigation. These data provide a unique opportunity to select cows that will and will not experience EM and to begin to dissect these biologically significant processes.

\section{ACKNOWLEDGMENTS}

The authors acknowledge the Food for the 21st Century Reproductive Biology cluster and the University of Missouri Research Board for financial support. In addition, we thank Idexx Laboratories for providing the commercial PAG assay reagents and plates for some of these experiments. The authors thank Tina Egen and Shannon Davies (Division of Animal Sciences, University of Missouri, Columbia) for their technical help with these experiments.

\section{REFERENCES}

Aires, M., K. Dekagi, V. Dantzer, and A. Yamada. 2014. Bovine placentome development during early pregnancy. Pages 390-396 in Microscopy: Advances in Scientific Research and Education. A. Méndez-Vilas, ed. Formatex, Badajoz, Spain.

Aono, F. H., R. F. Cooke, A. A. Alfieri, and J. L. Vasconcelos. 2013. Effects of vaccination against reproductive diseases on reproductive performance of beef cows submitted to fixed-timed AI in Brazilian cow-calf operations. Theriogenology 79:242-248.
Assis Neto, A. C., F. T. Pereira, T. C. Santos, C. E. Ambrosio, R. Leiser, and M. A. Miglino. 2010. Morpho-physical recording of bovine conceptus (Bos indicus) and placenta from days 20 to 70 of pregnancy. Reprod. Domest. Anim. 45:760-772.

Bellow, R., R. Staigmiller, J. Wilson, D. Phelps, and A. Darling. 1991. Use of bovine FSH for superovulation and embryo production in beef heifers. Theriogenology 35:1069-1082.

Breukelman, S. P., Z. Perenyi, M. A. Taverne, H. Jonker, G. C. van der Weijden, P. L. Vos, L. de Ruigh, S. J. Dieleman, J. F. Beckers, and O. Szenci. 2012. Characterisation of pregnancy losses after embryo transfer by measuring plasma progesterone and bovine pregnancyassociated glycoprotein-1 concentrations. Vet. J. 194:71-76.

Cartmill, J. A., S. Z. El-Zarkouny, B. A. Hensley, G. C. Lamb, and J. S. Stevenson. 2001a. Stage of cycle, incidence, and timing of ovulation, and pregnancy rates in dairy cattle after three timed breeding protocols. J. Dairy Sci. 84:1051-1059.

Cartmill, J. A., S. Z. El-Zarkouny, B. A. Hensley, T. G. Rozell, J. F. Smith, and J. S. Stevenson. 2001b. An alternative AI breeding protocol for dairy cows exposed to elevated ambient temperatures before or after calving or both. J. Dairy Sci. 84:799-806.

Chavatte-Palmer, P., N. de Sousa, P. Laigre, S. Camous, A. A. Ponter, J. F. Beckers, and Y. Heyman. 2006. Ultrasound fetal measurements and pregnancy associated glycoprotein secretion in early pregnancy in cattle recipients carrying somatic clones. Theriogenology 66:829-840.

Constant, F., S. Camous, P. Chavatte-Palmer, Y. Heyman, N. de Sousa, C. Richard, J. F. Beckers, and M. Guillomot. 2011. Altered secretion of pregnancy-associated glycoproteins during gestation in bovine somatic clones. Theriogenology 76:1006-1021.

Dalton, J. C., S. Nadir, J. H. Bame, M. Noftsinger, R. L. Nebel, and R. G. Saacke. 2001. Effect of time of insemination on number of accessory sperm, fertilization rate, and embryo quality in nonlactating dairy cattle. J. Dairy Sci. 84:2413-2418.

DeJarnette, J. M., R. G. Saacke, J. Bame, and C. J. Vogler. 1992. Accessory sperm: Their importance to fertility and embryo quality, and attempts to alter their numbers in artificially inseminated cattle. J. Anim. Sci. 70:484-491.

Farin, P. W., J. A. Piedrahita, and C. E. Farin. 2006. Errors in development of fetuses and placentas from in vitro-produced bovine embryos. Theriogenology 65:178-191.

FASS. 1999. Guide for the Care and Use of Agricultural Animals in Agricultural Research and Teaching. FASS, Champaign, IL.

Gajewski, Z., M. Petrajtis-Golobow, N. Melo de Sousa, J. F. Beckers, B. Pawlinski, and A. Wehrend. 2014. Comparison of accuracy of pregnancy-associated glycoprotein (PAG) concentration in blood and milk for early pregnancy diagnosis in cows. Schweiz. Arch. Tierheilkd. 156:585-590.

Green, J. A., T. E. Parks, M. P. Avalle, B. P. Telugu, A. L. McLain, A. J. Peterson, W. McMillan, N. Mathialagan, R. R. Hook, S. Xie, and R. M. Roberts. 2005. The establishment of an ELISA for the detection of pregnancy-associated glycoproteins (PAGs) in the serum of pregnant cows and heifers. Theriogenology 63:1481-1503.

Green, J. C., E. M. Newsom, and M. C. Lucy. 2011. Incorporation of a rapid pregnancy-associated glycoprotein ELISA into a CIDROvsynch resynchronization program for a 28 day re-insemination interval. Theriogenology 75:320-328.

Hill, J. R., R. C. Burghardt, K. Jones, C. R. Long, C. R. Looney, T. Shin, T. E. Spencer, J. A. Thompson, Q. A. Winger, and M. E. Westhusin. 2000. Evidence for placental abnormality as the major cause of mortality in first-trimester somatic cell cloned bovine fetuses. Biol. Reprod. 63:1787-1794.

Humblot, F., S. Camous, J. Martal, J. Charlery, N. Jeanguyot, M. Thibier, and R. G. Sasser. 1988. Pregnancy-specific protein B, progesterone concentrations and embryonic mortality during early pregnancy in dairy cows. J. Reprod. Fertil. 83:215-223.

Kirby, C. J., M. F. Smith, D. H. Keisler, and M. C. Lucy. 1997. Follicular function in lactating dairy cows treated with sustained-release bovine somatotropin. J. Dairy Sci. 80:273-285.

Lamb, G. C. 2002. Reproductive real-time ultrasound technology: An application for improving calf crop in cattle operations. Pages 235-253 in Factors Affecting Calf Crop: Biotechnology of Repro- 
duction. M. J. Fields, R. S. Sand, and J. V. Yelich, ed. CRC Press, Boca Raton, FL.

Lawson, B. C., A. H. Shahzad, K. A. Dolecheck, E. L. Martel, K. A. Velek, D. L. Ray, J. C. Lawrence, and W. J. Silvia. 2014. A pregnancy detection assay using milk samples: Evaluation and considerations. J. Dairy Sci. 97:6316-6325.

Leblanc, S. J. 2013. Short communication: Field evaluation of a pregnancy confirmation test using milk samples in dairy cows. J. Dairy Sci. 96:2345-2348.

Mercadante, P., K. Waters, V. Mercadante, G. Lamb, M. Elzo, S. Johnson, D. Rae, J. Yelich, and A. Ealy. 2013. Subspecies differences in early fetal development and plasma pregnancy-associated glycoprotein concentrations in cattle. J. Anim. Sci. 91:3693-3701.

Pereira, M. H., R. F. Cooke, A. A. Alfieri, and J. L. Vasconcelos. 2013. Effects of vaccination against reproductive diseases on reproductive performance of lactating dairy cows submitted to AI. Anim. Reprod. Sci. 137:156-162.

Perry, G. A., M. F. Smith, M. C. Lucy, J. A. Green, T. E. Parks, M. D. MacNeil, A. J. Roberts, and T. W. Geary. 2005. Relationship between follicle size at insemination and pregnancy success. Proc. Natl. Acad. Sci. USA 102:5268-5273.

Pfarrer, C. D., S. D. Ruziwa, H. Winther, H. Callesen, R. Leiser, D. Schams, and V. Dantzer. 2006. Localization of vascular endothelial growth factor (VEGF) and its receptors VEGFR-1 and VEGFR-2 in bovine placentomes from implantation until term. Placenta $27: 889-898$.

Pohler, K. G., T. W. Geary, C. L. Johnson, J. A. Atkins, E. M. Jinks, D. C. Busch, J. A. Green, M. D. MacNeil, and M. F. Smith. 2013. Circulating bovine pregnancy associated glycoproteins are associated with late embryonic/fetal survival but not ovulatory follicle size in suckled beef cows. J. Anim. Sci. 91:4158-4167.

Pohler, K. G., J. Green, L. A. Moley, K. M. Doran, H. B. Graff, R. F. Peres, J. L. Vasconcelos, and M. F. Smith. 2014. The effect of embryonic size and sire on circulating concentrations of bovine pregnancy associated glycoproteins (PAGs) in beef cows. Page 565 in Reprod. Fert.: Proc. 9th Int. Rumin. Reprod. Symp. Context Products Ltd., Leicestershire, UK.

Ribeiro, E. S., R. L. Cerri, R. S. Bisinotto, F. S. Lima, F. T. Silvestre, L. F. Greco, W. W. Thatcher, and J. E. Santos. 2011. Reproductive performance of grazing dairy cows following presynchronization and resynchronization protocols. J. Dairy Sci. 94:4984-4996.

Ribeiro, E. S., F. S. Lima, L. F. Greco, R. S. Bisinotto, A. P. Monteiro, M. Favoreto, H. Ayres, R. S. Marsola, N. Martinez, W. W. Thatcher, and J. E. Santos. 2013. Prevalence of periparturient diseases and effects on fertility of seasonally calving grazing dairy cows supplemented with concentrates. J. Dairy Sci. 96:5682-5697.

Ribeiro, E. S., A. P. Monteiro, F. S. Lima, H. Ayres, R. S. Bisinotto, M. Favoreto, L. F. Greco, R. S. Marsola, W. W. Thatcher, and J. E. Santos. 2012. Effects of presynchronization and length of proestrus on fertility of grazing dairy cows subjected to a 5-day timed artificial insemination protocol. J. Dairy Sci. 95:2513-2522.

Ricci, A., P. D. Carvalho, M. C. Amundson, R. H. Fourdraine, L. Vincenti, and P. M. Fricke. 2015. Factors associated with pregnancyassociated glycoprotein (PAG) levels in plasma and milk of Holstein cows during early pregnancy and their effect on the accuracy of pregnancy diagnosis. J. Dairy Sci. 98:2502-2514.

Romano, J. E., and J. E. Larson. 2010. Accuracy of pregnancy specific protein-B test for early pregnancy diagnosis in dairy cattle. Theriogenology 74:932-939.

Sartori, R., R. Sartor-Bergfelt, S. A. Mertens, J. N. Guenther, J. J. Parrish, and M. C. Wiltbank. 2002. Fertilization and early em- bryonic development in heifers and lactating cows in summer and lactating and dry cows in winter. J. Dairy Sci. 85:2803-2812.

Sasser, R. G., C. A. Ruder, K. A. Ivani, J. E. Butler, and W. C. Hamilton. 1986. Detection of pregnancy by radioimmunoassay of a novel pregnancy-specific protein in serum of cows and a profile of serum concentrations during gestation. Biol. Reprod. 35:936-942.

Schallenberger, E., D. Schams, and H. H. Meyer. 1989. Sequences of pituitary, ovarian and uterine hormone secretion during the first 5 weeks of pregnancy in dairy cattle. J. Reprod. Fertil. Suppl. $37: 277-286$.

Silke, V., M. G. Diskin, D. A. Kenny, M. P. Boland, P. Dillon, J. F Mee, and J. M. Sreenan. 2002. Extent, pattern and factors associated with late embryonic loss in dairy cows. Anim. Reprod. Sci. 71:1-12.

Silva, E., R. A. Sterry, D. Kolb, N. Mathialagan, M. F. McGrath, J. M. Ballam, and P. M. Fricke. 2007. Accuracy of a pregnancyassociated glycoprotein ELISA to determine pregnancy status of lactating dairy cows twenty-seven days after timed artificial insemination. J. Dairy Sci. 90:4612-4622.

Silva, E., R. A. Sterry, D. Kolb, N. Mathialagan, M. F. McGrath, J. M. Ballam, and P. M. Fricke. 2009. Effect of interval to resynchronization of ovulation on fertility of lactating Holstein cows when using transrectal ultrasonography or a pregnancy-associated glycoprotein enzyme-linked immunosorbent assay to diagnose pregnancy status. J. Dairy Sci. 92:3643-3650.

Sousa, N. M., A. Ayad, J. F. Beckers, and Z. Gajewski. 2006. Pregnancy-associated glycoproteins (Pag) as pregnancy markers in the ruminants. J. Physiol. Pharmacol. 57(Suppl. 8):153-171.

Starbuck, M. J., R. A. Dailey, and E. K. Inskeep. 2004. Factors affecting retention of early pregnancy in dairy cattle. Anim. Reprod. Sci. 84:27-39.

Szafranska, B., G. Panasiewicz, and M. Majewska. 2006. Biodiversity of multiple Pregnancy-Associated Glycoprotein (PAG) family: Gene cloning and chorionic protein purification in domestic and wild eutherians (Placentalia) - A review. Reprod. Nutr. Dev. 46:481-502.

Thompson, I. M., R. L. Cerri, I. H. Kim, J. A. Green, J. E. Santos, and W. W. Thatcher. 2010. Effects of resynchronization programs on pregnancy per artificial insemination, progesterone, and pregnancy-associated glycoproteins in plasma of lactating dairy cows. J. Dairy Sci. 93:4006-4018.

Vasconcelos, J. L. M., R. W. Silcox, J. A. Lacerda, J. R. Pursley, and M. C. Wiltbank. 1997. Pregnancy rate, pregnancy loss, and response to heat stress after AI at 2 different times from ovulation in dairy cows. Biol. Reprod. 56(Suppl. 1):140.

Wallace, J. M., R. P. Aitken, M. A. Cheyne, and P. Humblot. 1997. Pregnancy-specific protein $\mathrm{B}$ and progesterone concentrations in relation to nutritional regimen, placental mass and pregnancy outcome in growing adolescent ewes carrying singleton fetuses. J. Reprod. Fertil. 109:53-58.

Wallace, R. M., K. G. Pohler, M. F. Smith, and J. A. Green. 2015. Placental PAGs: Gene origins, expression patterns, and use as markers of pregnancy. Reproduction 149:R115-R126.

Wildman, E. E., G. M. Jones, P. E. Wagner, R. L. Boman, H. F. Troutt, and T. N. Lesch. 1982. A dairy cows body condition scoring system and its relationship to selected production characteristics. J. Dairy Sci. 65:495-501.

Zoli, A. P., L. A. Guilbault, P. Delahaut, W. B. Ortiz, and J. F. Beckers. 1992. Radioimmunoassay of a bovine pregnancy-associated glycoprotein in serum: Its application for pregnancy diagnosis. Biol. Reprod. 46:83-92. 